\author{
Military Technical College \\ Kobry El-Kobbah, \\ Cairo, Egypt.
}

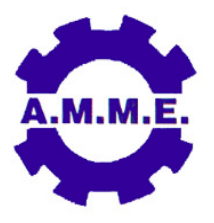
$17^{\text {th }}$ International Conference on Applied Mechanics and Mechanical Engineering.

\title{
CFD INVESTIGATION OF SMOKE MANAGEMENT IN UNDERGROUND TUNNEL
}

\author{
W. M. Sweida*, O. A. Huzzain ${ }^{\star \star}$ and E. E. Khaliil ${ }^{\star \star *}$
}

\begin{abstract}
A mechanical ventilation system plays a major role in tunnels safety. Over the world, different ventilation systems regarding to the tunnel geometry and other parameters are used for tunnel ventilation in the normal and fire operations. The main concern is a proper smoke evacuation in a fire case. In this paper, we are studying the mechanical ventilation system in underground tunnel below Suez Canal -Egypt that were simulated using Fire Dynamic Simulator (FDS) version 6.2.0, and it shows an acceptable agreement with experimental data. The studied parameters included the temperature variation along tunnel length, and the variation in temperature at different crosssections and heights and velocity variation with time at different heights and crosssections in order to assess the effectiveness of various ventilation scenarios at fire accidents within the tunnel. The results have been presented and analyzed to simulate an actual fire test in some locations inside the tunnel.
\end{abstract}

Three case studies simulated with different Heat Release Rate(HRR)of Heptane pool with 29MW, which equivalent to bus or truck fire, 67MW which is equivalent to plastic cups goods vehicles fire (HGV)and $119 \mathrm{MW}$ which equivalent trailer with 8.5 ton furniture, fixtures and rubber tires [1]. The fire location is fixed at $105 \mathrm{~m}$ from tunnel entrance. Results illustrate the temperature contours and velocity contours at different cross sections at human level. This study shows that temperature at human level doesn't exceed $40^{\circ} \mathrm{C}$.

\section{KEY WORDS}

Smoke Management, Tunnel Fire, HRR, Jet Fan, and tunnel ventilation.

* $\quad$ PhD. Graduate student, Dept. of Mech. Power, Cairo University, Giza, Egypt.

** Assistant professor, Dept. of Mechanical Power Engineering, Cairo University, Cairo, Egypt.

*** Professor, Dept. of Mechanical Power Engineering, Cairo University, Giza, Egypt. 


\section{NOMENCLATURE}

$\begin{array}{cl}\text { Symbol } & \text { Quantity } \\ \mathrm{g} & \text { Gravitational acceleration, } \mathrm{m} / \mathrm{s}^{2} \\ \mathrm{H} & \text { Height, } \mathrm{m} \\ \mathrm{L} & \text { Length, } \mathrm{m} \\ \mathrm{P} & \text { Pressure, } \mathrm{Pa} \\ \mathrm{t} & \text { Time, } \mathrm{s} \\ \mathrm{T} & \text { Temperature, } \mathrm{C} \\ \mathrm{U} & \text { Axial velocity, } \mathrm{m} / \mathrm{s}-\text { Average velocity near the wall region, } \mathrm{m} / \mathrm{s}\end{array}$

\section{INTRODUCTION}

In recent years, disastrous tunnel fires have accidentally occurred, such as the Korea Daegu Fire in 2003, killing 189 people and the Viamala Tunnel Fire in Switzerland in 2006, killing nine people [2]. The fire-induced smoke will influence the safe evacuation of occupants and prevent the fire fighters from extinguishing the fire. According to statistics $85 \%$ of the deaths in building fires were caused by the toxic smoke [3]. Many experimental and CFD studies, all over the world, have been conducted in order to evaluate the impact of the airflow on temperature and smoke distributions during the fire in tunnels $[4,5,6]$.During fires, the accumulation of heat generated by fires can cause the temperature of the confined space to rise significantly. The hot smoke, even the fire flame, will directly contact the tunnel structure. The strength of the steel bars in the concrete is reduced once the bars are exposed to flame and hot smoke, which eventually leads to sinking or collapse of the tunnel ceiling [7]. Other than the structural issue, sprinklers or detectors installed in tunnels are quite likely to be activated by the smoke travelling along the ceiling. Therefore, it is in practice worth studying the maximum smoke temperature under the tunnel ceiling so as to enhance the safety level in tunnels. All road tunnels require ventilation to remove the contaminants produced by vehicle engines during normal operation.

Ventilation may be provided by natural means, by the traffic-induced piston effect or by mechanical equipment. The selected method should be the most economically in terms of construction and operating costs. Ventilation must also be considered for road tunnels to provide the necessary control of smoke and heated gases resulting from a fire within the tunnel and to keep the environment suitable for emergency evacuation and rescue in the evacuation path. The cutting-edge technology for representing the complex physics of fire and smoke propagation in the simulation space is computational fluid dynamics (CFD) by using fire dynamic simulator (FDS). This methodology solves the fundamental equations describing fluid flow: the timedependent Navier-Stokes equations; and the issues surrounding the heat transfer phenomena associated with fire. In addition, it is necessary to couple the combustion chemistry of the processes with the equations describing the transport of species. With 
these elements and sufficient computer power, it is possible to predict the spread of fire and smoke in arbitrary geometries in a realistic way. In spite of the maturity of CFD technology, fire dynamic simulator proves its validity all over its results. Our case for a tunnel under construction passing below Suez Canal - Egypt, its length is $300 \mathrm{~m}$ and width is 10 meter, and 6 meter height.

When a fire is started on the floor of a straight tunnel without a ventilation flow, a hot plume rises above the fire and entrains the surrounding cold air into the plume. The plume, upon reaching the ceiling, forms two gas streams flowing in opposite directions along the ceiling. When a cross ventilation current exists, the symmetry in the rising plume and in the ceiling gas streams is broken. The ventilation current bends the plume and the length of the ceiling layer flowing against the ventilation current is reduced. For the trapped occupants and fire fighters to see clearly the way out or the way to fire origin, the longitudinal ventilation velocity should be larger than a critical value to prevent back-layering. The critical longitudinal ventilation velocity is one of the key criteria used for designing tunnel ventilation systems. The critical velocity $\left(\mathrm{V}_{\text {critical }}\right)$ is defined as the minimum air velocity required to prevent the occurrence of back layering [8].Motorists should not be exposed to maximum air temperatures that exceed $60^{\circ} \mathrm{C}$ $\left(140^{\circ} \mathrm{F}\right)$ during emergencies to provide safety according to NFPA 502 [9].

Ventilation is necessary in most road tunnels to limit the concentrations of contaminants to acceptable levels within the traveled roadway. Ventilation systems can also be used to control smoke and heated gases that are generated during a tunnel fire emergency. Some short tunnels are ventilated naturally (without fans); however, such tunnels could necessitate ventilation to combat a fire emergency. A longitudinal ventilation system introduces air into, or removes air from, the tunnel roadway at a limited number of points, such as a portal or a shaft, thus creating a longitudinal flow of air within the roadway, with discharge at the exiting portal. Transverse ventilation systems feature the uniform collection or distribution of air throughout the length of the tunnel and can be of the full transverse or semi transverse type. In addition, semi transverse systems can be of the supply or exhaust type.

For the jet fan system, Jet fans are mounted on the ceiling and achieve their effect by means of the thrust (impulse) of the air outflow. A high induction of the surrounding air is produced, and after a short time the volume of air in the entire space begins to circulate. This effect results in the transferred volume of air being several times greater than the actual flow volume of the fan. In the present work, three case studies simulated with different Heat Release Rate(HRR)of Heptane pool with 29MW, 67MW, and $119 \mathrm{MW}$ in order to illustrate the temperature contours at different cross sections in the tunnel at human level.

\section{CFD MODELING}

Following is a brief description of the major components of the Fire Dynamics Simulator (FDS) [10]. 


\section{Hydrodynamic Model}

FDS solves numerically a form of the Navier-Stokes equations appropriate for the lowspeed, thermally-driven flow with an emphasis on the smoke and heat transport from fires. FDS model solves a form of conservation equations for low speed, thermally driven flow [11]. The core algorithm is an explicit predictor-corrector scheme that is second order accurate in space and time. Turbulence is treated by means of Large Eddy Simulation (LES). It is possible to perform a Direct Numerical Simulation (DNS) if the underlying numerical grid is fine enough. LES is the default mode of operation.

\section{Combustion Model}

For most applications, FDS uses a combustion model based on the mixture fraction concept. The mixture fraction is a conserved scalar quantity that is defined as the fraction of gas at a given point in the flow field that originates as fuel. The reaction of fuel and oxygen is not necessarily instantaneous and complete, and there are several optional schemes that are designed to predict the extent of combustion in underventilated spaces. The mass fractions of all of the major reactants and products can be derived from the mixture fraction by means of "state relations," expressions arrived at by a combination of simplified analysis and measurement.

\section{Radiation Transport}

Radiative heat transfer is included in the model via the solution of the radiation transport equation for a gray gas. In a limited number of cases, a wide band model can be used in place of the gray gas model to provide a better spectral accuracy. The radiation equation is solved using a technique similar to a finite volume method for convective transport, thus the name given to it is the Finite Volume Method (FVM).

\section{Boundary Conditions}

All solid surfaces are assigned thermal boundary conditions, plus information about the burning behavior of the material. Heat and mass transfer to and from solid surfaces is usually handled with empirical correlations, although it is possible to compute directly the heat and mass transfer when performing a Direct Numerical Simulation (DNS).

\section{NUMERICAL VALIDATION}

The validation process for FDS are carried out using experiment which is presented by Blanchard et al [12] in underground tunnel. FDS is used for provide same tunnel model which was presented by Blanchard et al [12] who studied the experimental variation of temperature with time in different heights and sections of tunnel, the temperature distribution along tunnel length, variation of heat release rate of Heptane fire pool with time and velocity variation with time at different heights and cross sections upstream and downstream of fire location. The case of Blanchard et al [12] is horizontal tunnel, completely belowground and $43 \mathrm{~m}$ long, with a partial cross section around $4 \mathrm{~m} 2$ in surface and with a $2.16 \mathrm{~m}$ hydraulic diameter. The walls are covered by a fire resistant mortar cement with well-known thermal properties. The floor is made of concrete. A 
ventilation device is mounted at the downstream side of the tunnel in order to control the longitudinal flow rate by extracting a roughly constant gas volume flux. The fire load is provided by a Heptane pool at a central location on the transverse section. The steel pool has a $0.5 \mathrm{~m} 2$ area and $0.1 \mathrm{~m}$ depth. The HRR would be around $1.5 \mathrm{MW}$ in an open space (approximately correspond to $23 \mathrm{MW}$ according to Oka and Atkinson scaling methods [13]).

The critical ventilation velocity has been evaluated using various well-known methods as reported in Table 1. This critical velocity allows preventing back layering, i.e. all the combustion gases are transported downstream the fire. The ventilation velocity, which presented by Blanchard et al [12], have been performed with an exhausted volumetric rate of $4.0 \mathrm{~m}^{3} / \mathrm{s}$ and $8.8 \mathrm{~m}^{3} / \mathrm{s}$ corresponding to a longitudinal velocity of $1.0 \mathrm{~m} / \mathrm{s}$ and $2.2 \mathrm{~m} / \mathrm{s}$ without fire. The present work carried out FDS simulation of tunnel which presented by Blanchard et al [12] in real scale. The dimensions of real scale equal the dimension of model multiple to 3 . Velocity and fire heat release rate of real scale produced by using Oka and Atkinson [13] methods for scaling as shown in the Table 2. The dimensions of real scale tunnel are divided into cubic cells of $30 \mathrm{~cm} \times 30 \mathrm{~cm} \times 30$ $\mathrm{cm}$ in FDS modeling. The total number of cells in real scale tunnel is 204,250 cell.

The results present the comparison between FDS simulation results and Blanchard et al [12] experimental study. The HRR Which presented by FDS simulation provided an acceptable agreement with HRR data presented by Blanchard et al [12] as shown in Figure 1 and Figure 2. A first step of rapid increase is observed during the first $90 \mathrm{~s}$, then the increase is weaker but the experiment does not show a steady state. Finally, there is a sharp HRR peak around $350 \mathrm{~s}$, before a rapid decrease. The observed increase arises due to the radiant energy emitted from the wall surfaces progressively heated (feedback loop). This sharp peak up to $3.4 \mathrm{MW}$ at the end of the test, results from an increasing volume temperature of the fuel (all the substrate reaches the boiling point).

The temperature is presented as a function of time at $27 \mathrm{~m}$ upstream the fire section, along a vertical central line. FDS simulation for temperature provided an acceptable agreement with experimental data presented by Blanchard et al [12] in 27m upstream the fire at height $5.4 \mathrm{~m}$ and $4.5 \mathrm{~m}$ as shown in Figure 3 and Figure 4 . Based on previous validation results proved that FDS version 6.2.0 simulation results, have an acceptable agreement with experimental data presented by Blanchard et al [12].

\section{TUNNEL MODEL CONFIGURATION}

The tunnel is horizontal and completely below ground. It is $300 \mathrm{~m}$ long, with a rectangle cross-section. ventilation devices are mounted by groups of jet fans under tunnel ceiling with $100 \mathrm{~m}$ distant apart as shown in Figure 5. The tunnel is divided into three ventilation zones each is $100 \mathrm{~m}$ long. 8 fans with $100 \mathrm{~m}$ apart are located inside the tunnel for smoke evacuation and ventilation process as shown in Figure 6. When a fire occurs in a tunnel, the existing ventilation system has to be able to control the smoke propagation. In the case of longitudinal or transverse ventilation systems, one of the main aspects deals with the preservation of the smoke's natural stratification. So it 
must be preserved in a clean air layer in the lower part of the tunnel, which is crucial in order to facilitate the motorists' evacuation.

After motorists evacuating, jet fans start to work at highest speed that is cause to sweep all smoke upstream the fire to downstream to allow fire fighters enter from traffic direction. Due to high speed from jet fans, the smoke plume starts to tilt and fill the lower part of tunnel. The present work studies the effect of fire heat release rate (HRR) of $29 \mathrm{MW}$, which was equivalent to bus or truck fire, $67 \mathrm{MW}$ which equivalent to plastic cups goods vehicles fire (HGV) and $119 \mathrm{MW}$ which equivalent to trailer with 8.5 ton furniture, fixtures and rubber tires, and fire location in zone 2 on temperature, and velocity.

In this present study, number of cells was estimated to be about 800000 mesh cells. It provided more accurate results according to grid sensitivity analysis. Ambient Temperature is $20^{\circ} \mathrm{C}$ as an average temperature all over the year within Egypt region, ambient pressure is $1.013 \times 10^{5} \mathrm{~Pa}$, relative Humidity $50 \%$, normal ventilation velocity in tunnel under non thermal condition (without fire) is $1 \mathrm{~m} / \mathrm{s}$ and jet fans flow rate is 21 $\mathrm{m}^{3} / \mathrm{s}$.

\section{Grid Sensitivity Analysis}

A grid sensitivity study is performed to optimize the computational resources. Three meshes give the total control volumes of 90,192 cells (coarse grid), 800,0000 cells (medium grid) and 1,200,790 cells (fine grid). The resultant temperatures, which is at 9m upstream fire location and height $5.4 \mathrm{~m}$ in case of $29 \mathrm{mw}$ HRR, show in Figure 7. It shows that medium and fine grids give similar results and the average relative error for coarse grid and fine grid with respect to medium grid are $23 \%$ and $5.8 \%$ respectively. It is therefore concluded that the resolution of the medium grid should be sufficient and predictions here after are all based on the medium grid system.A set of different FDS sensors are locates in different location, in order to get complete analysis for each measured parameter and for every case as per Table 3.

\section{Simulation of Case \#1}

The temperature contours are presented in Figures 8, 9, and 10 as a function of time at location of $50 \mathrm{~m}$ downstream fire location which shows that the maximum temperature under tunnel ceiling just before working of jet fans didn't exceed $220^{\circ} \mathrm{C}$. After working of jet fans at time 150s the maximum temperature under tunnel ceiling reduced to $170 \mathrm{C}$ and the temperature at human level reached to120C.

The temperature contours as a function of time at human level and mid plane in zone \#2 show that the maximum temperature under tunnel ceiling reaches to $315^{\circ} \mathrm{C}$ and the temperature at human level is $20^{\circ} \mathrm{C}$ at time 100 s to enhance evacuation process. At time $150 \mathrm{~s}$ the temperature reaches to $80^{\circ} \mathrm{C}$ at human level due to plume tilting and the temperature under tunnel ceiling reaches to $230^{\circ} \mathrm{C}$. At time $300 \mathrm{~s}$ the temperature decreases to $60^{\circ} \mathrm{C}$ at human level, as shown in the above Figures 11, 12, and 13 .

For the temperature distribution, we located sensors at human level in order to get complete longitudinal thermal distributions over tunnel length as shown in Figures 14, 
which shows longitudinal temperature distribution at time 100s and 300s in upstream region. It's noticed that the temperature at $100 \mathrm{~s}$ is $22^{\circ} \mathrm{C}$ and it increasing with getting closer to fire location. The temperature at time $300 \mathrm{~s}$, after working of jet fans, decreasing to $20^{\circ} \mathrm{C}$ due to smoke sweeping from upstream region.

Figure 15 shows longitudinal temperature distribution at human level at time 100s and $300 \mathrm{~s}$ in downstream region. It's noticed that the temperature at time $100 \mathrm{~s}$ is $22^{\circ} \mathrm{C}$ and the temperature at time $300 \mathrm{~s}$ increases to $50^{\circ} \mathrm{C}$ due to plume tilting and smoke sweeping from upstream region.

The velocity contours as a function of time at mid plane $(y=3.7 \mathrm{~m})$ in zone \#2 show that the velocity of ceiling jet, which define as the flow of smoke under tunnel ceiling, extending from the point of fire plume impingement on ceiling, reached to $6.5 \mathrm{~m} / \mathrm{s}$ at time 100s. At time $150 \mathrm{~s}$ the velocity increased to $9.5 \mathrm{~m} / \mathrm{s}$ and it was noticed at fire point that the smoke raised with high momentum that reduced fan velocity. At time 300 $\mathrm{s}$ the velocities remained constant and reached to steady state condition as shown in figures 16,17 , and 18.

\section{Simulation of Case \#2}

The temperature contours are presented in Figures 19, 20 and 21 as a function of time at location of $50 \mathrm{~m}$ downstream fire location, which shows that the maximum temperature under tunnel ceiling just before working of jet fans doesn't exceed $370{ }^{\circ} \mathrm{C}$. After working of jet fans at time $150 \mathrm{~s}$ the maximum temperature under tunnel ceiling reduces to $335^{\circ} \mathrm{C}$ and the temperature at human level reaches to $125 \mathrm{C}$. The temperature contours as a function of time at human level and mid plane in zone \#2 show that the maximum temperature under tunnel ceiling reaches to $650^{\circ} \mathrm{C}$ and the temperature at human level is $20^{\circ} \mathrm{C}$ at time $100 \mathrm{~s}$ to enhance evacuation process. At time $150 \mathrm{~s}$ the temperature reaches to $120^{\circ} \mathrm{C}$ at human level due to plume tilting and the temperature under tunnel ceiling reaches to $4500^{\circ} \mathrm{C}$, at time $300 \mathrm{~s}$ the temperature reaches $100^{\circ} \mathrm{C}$ at human level, as shown in Figures 22, 23 and 24.

Figure 25 which shows longitudinal temperature distribution at time $100 \mathrm{~s}$ and $300 \mathrm{~s}$ in upstream region. It's noticed that the temperature at time $100 \mathrm{sec}$ is $24^{\circ} \mathrm{C}$ and it increasing with getting closer to fire location. The temperature at time $300 \mathrm{~s}$, after working of jet fans, decreases to $20^{\circ} \mathrm{C}$ due to smoke sweeping from upstream region. Figure 26 shows longitudinal temperature distribution at human level at time $100 \mathrm{~s}$ and $300 \mathrm{~s}$ in downstream region. It's noticed that the temperature at time $100 \mathrm{~s}$ is $20^{\circ} \mathrm{C}$. and it increasing with getting closer to fire location, and the temperature at time $300 \mathrm{~s}$ increases to $80^{\circ} \mathrm{C}$ due to smoke sweeping from upstream region. The velocity contours as a function of time at mid plane in zone \#2 show that the velocity of ceiling jet reaches to $6.5 \mathrm{~m} / \mathrm{s}$ at time $100 \mathrm{~s}$. At time $150 \mathrm{~s}$ the velocity increases to $9.5 \mathrm{~m} / \mathrm{s}$ and it is noticed at fire point that the smoke rises with high momentum which reduce fan velocity, that locate near from fire point. At time $300 \mathrm{~s}$ the velocities remain constant and reach to steady state condition as shown in figures 27, 28, and 29.

\section{Simulation of Case \#3}

The temperature contours are presented in Figures 30, 31, and 32 as a function of time 
at location of $50 \mathrm{~m}$ downstream fire location which shows that the maximum temperature under tunnel ceiling just before working of jet fans doesn't exceed $420^{\circ} \mathrm{C}$. After working of jet fans at time $150 \mathrm{~s}$ the maximum temperature under tunnel ceiling increases to $520^{\circ} \mathrm{C}$ and the temperature at human level reaches to $170^{\circ} \mathrm{C}$.

The temperature contours as a function of time at human level and mid plane in zone \#2 show that the maximum temperature under tunnel ceiling reaches to $820^{\circ} \mathrm{C}$ and the temperature at human level is $20^{\circ} \mathrm{C}$ at time $100 \mathrm{~s}$ to enhance evacuation process.

At time $150 \mathrm{~s}$ the temperature reaches to $380^{\circ} \mathrm{C}$ at human level due to plume tilting and the temperature under tunnel ceiling remains constant. At time $300 \mathrm{~s}$ the temperature reaches $200{ }^{\circ} \mathrm{C}$ at human level as shown in Figures 33, 34 and 35.

Thermocouples sensors are located at human level in order to get complete longitudinal thermal distributions over tunnel length as shown in figure 36, which shows longitudinal temperature distribution at time 100 s and 300 s in upstream region.

It is noticed that the temperature at time $100 \mathrm{sec}$ is $40^{\circ} \mathrm{C}$ and it increases with getting closer to fire location. The temperature at time 300s, after operation of jet fans, decreases to $20^{\circ} \mathrm{C}$ due to smoke sweeping from upstream region. Figure 37 shows longitudinal temperature distribution at human level at time $100 \mathrm{~s}$ and $300 \mathrm{~s}$ in downstream region. It's noticed that the temperature at time $100 \mathrm{~s}$ is $40{ }^{\circ} \mathrm{C}$. and it increasing with getting closer to fire location, and the temperature at time $300 \mathrm{~s}$ increases to $160^{\circ} \mathrm{C}$ due to smoke sweeping from upstream region.

The velocity contours as a function of time at mid plane in zone \#2 show that the velocity of ceiling jet reaches to $6 \mathrm{~m} / \mathrm{s}$ at time 100s. At time $150 \mathrm{~s}$ the velocity increases to $10 \mathrm{~m} / \mathrm{s}$ due to jet fans flow and it's noticed at fire point that the smoke rises with high momentum which reduce fan velocity, that locate near from fire point. At time $300 \mathrm{~s}$ the velocities remain constant and reach to steady state condition as shown in figures 38 , 39 , and 40.

\section{CONCLUSIONS}

Fire Dynamic Simulator (FDS) showed an acceptable agreement with experimental data, which was presented by Blanchard et al. [12]. The agreement parameters included the temperature variation along tunnel length and the variation in temperature at different cross-sections and heights. The grid size employed in this study is adequate to predict the various parameters of temperature, and velocity according to grid sensitivity analysis. The numerical results, which were obtained by FDS, showed that increasing in fire Heat Release Rate (HRR) increased the maximum temperature under tunnel ceiling and increased also the temperature at human level but in worst case of HRR equal $119 \mathrm{MW}$ the temperature reached to $40 \mathrm{C}^{\circ}$ which is still under safety limit according to NFPA 502[9].

The numerical results that were obtained by FDS confirmed that the standard calculation method for jet fan design as per ASHRAE and NFPA 502 [9] recommendations is acceptable for our case. 
Table 1. Critical ventilation velocities.

\begin{tabular}{|l|c|c|c|}
\hline HRR & Oka's method[13] & Wu's method [14] & Kunsch's method [15] \\
\hline $1.5 \mathrm{MW}$ & $1.5 \mathrm{~m} / \mathrm{s}$ & $1.2 \mathrm{~m} / \mathrm{s}$ & $1.8 \mathrm{~m} / \mathrm{s}$ \\
\hline
\end{tabular}

Table 2. Scaling data.

\begin{tabular}{|l|c|c|}
\hline & $\begin{array}{c}\mathbf{1 / 3} \text { scale model } \\
\text { (Blanchard et al[12] })\end{array}$ & $\begin{array}{c}\text { Real scale model } \\
\text { (FDS Simulation ) }\end{array}$ \\
\hline Tunnel Height $(\mathrm{m})$ & 1.9 & 5.7 \\
\hline Tunnel Width $(\mathrm{m})$ & 2.5 & 7.5 \\
\hline Tunnel long $(\mathrm{m})$ & 43 & 129 \\
\hline $\begin{array}{l}\text { Velocity in below critical } \\
\text { velocity condition (m/s) }\end{array}$ & 1 & 1.73 \\
\hline $\begin{array}{l}\text { Velocity in above critical } \\
\text { velocity condition(m/s) }\end{array}$ & 2.2 & 3.8 \\
\hline HRR (MW) & 1.5 & 23 \\
\hline
\end{tabular}

Table 3. Case Studies.

\begin{tabular}{|c|c|c|}
\hline Case & Fire Location & $\begin{array}{c}\text { Heat Release Rate of } \\
\text { Fire(HRR)(MW) }\end{array}$ \\
\hline Case 1 & At 105m from tunnel entrance (at first of Zone \#2) & $29 \mathrm{MW}$ \\
\hline Case 2 & At 105m from tunnel entrance (at first of Zone \#2) & $67 \mathrm{MW}$ \\
\hline Case 3 & At 105m from tunnel entrance (at first of Zone \#2) & $119 \mathrm{MW}$ \\
\hline
\end{tabular}

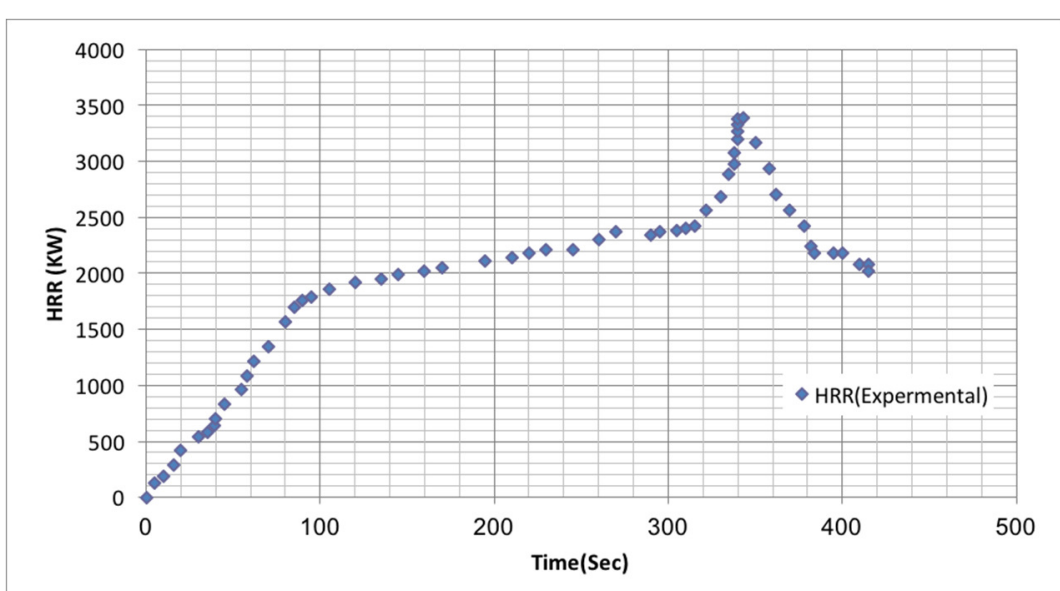

Fig. 1. HRR of fire presented by Blanchard et al [12]. 


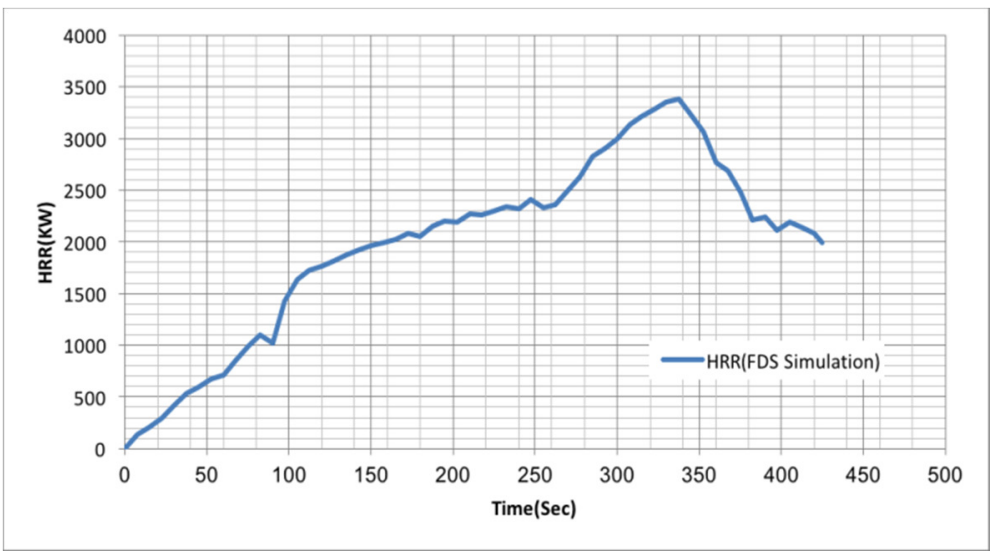

Fig. 2. HRR of fire presented by FDS by simulation.

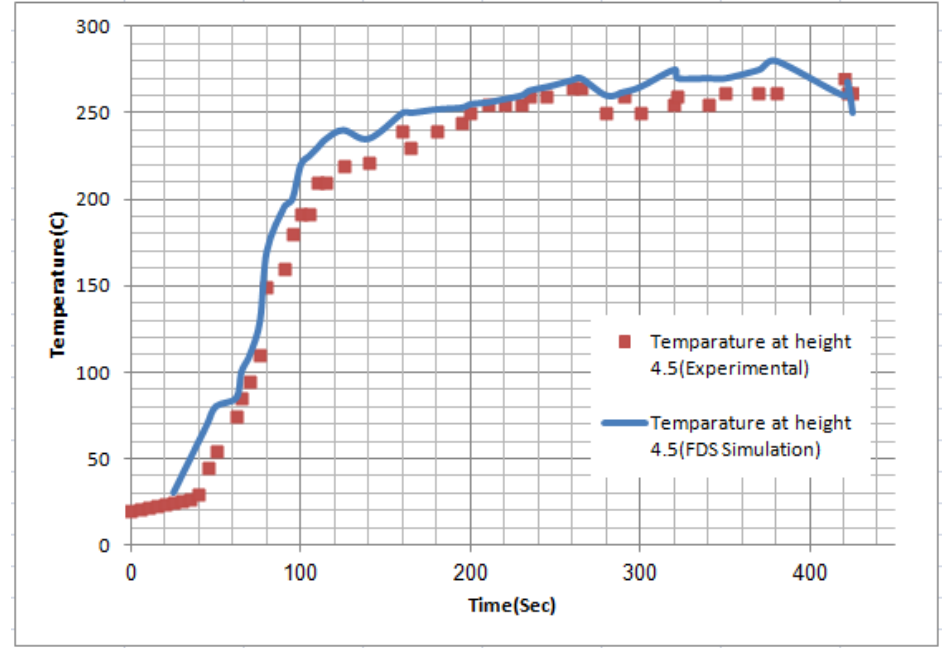

Fig. 3. Temperature variation with time at $27 \mathrm{~m}$ upstream the fire at height $4.5 \mathrm{~m}$.

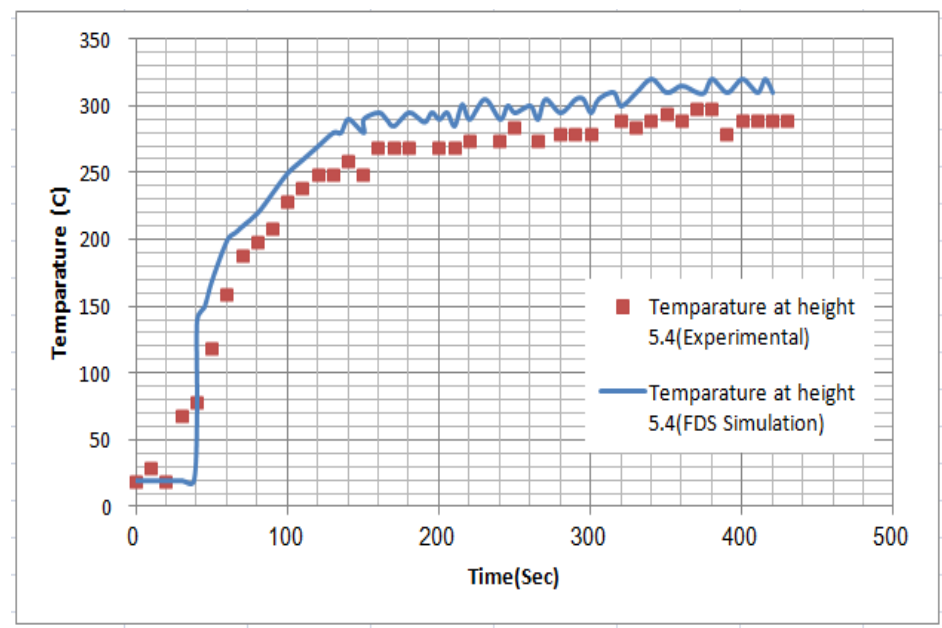

Fig. 4. Temperature variation with time at $27 \mathrm{~m}$ upstream the fire at height $5.4 \mathrm{~m}$. 


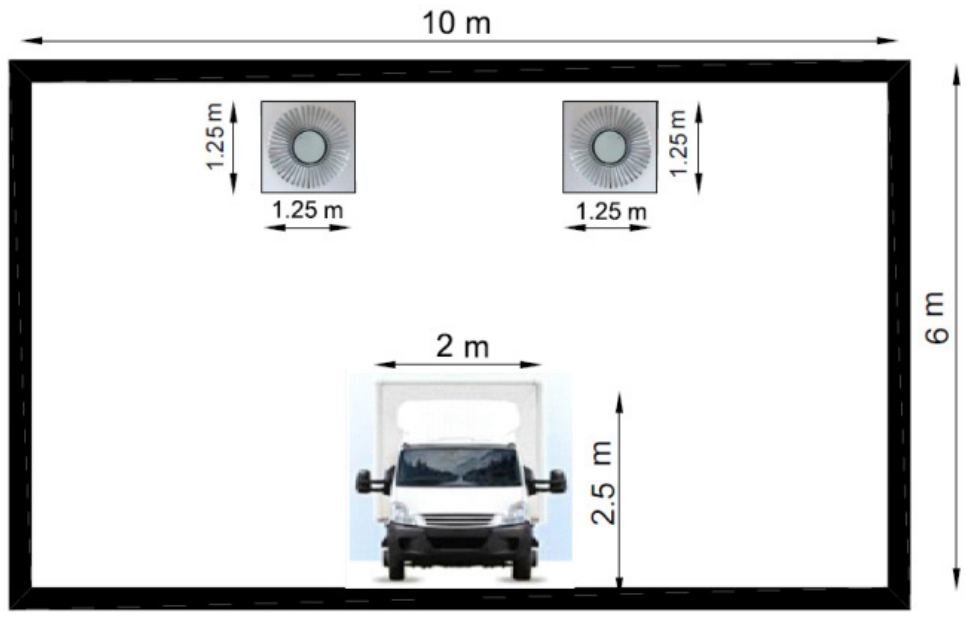

Fig. 5. Tunnel cross-section.

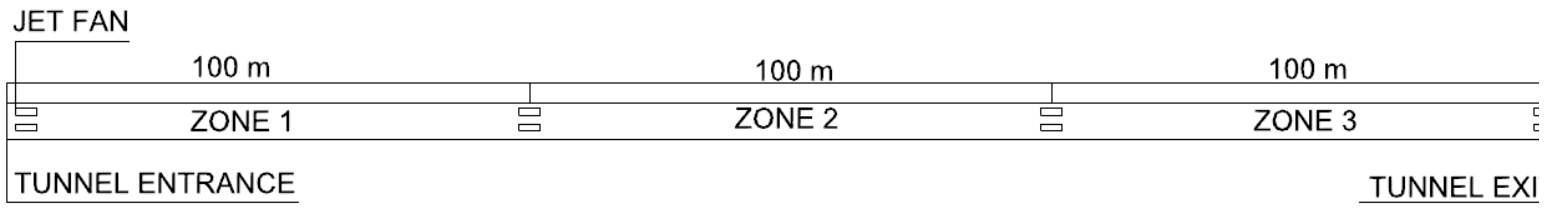

Fig. 6. Model of Tunnel.

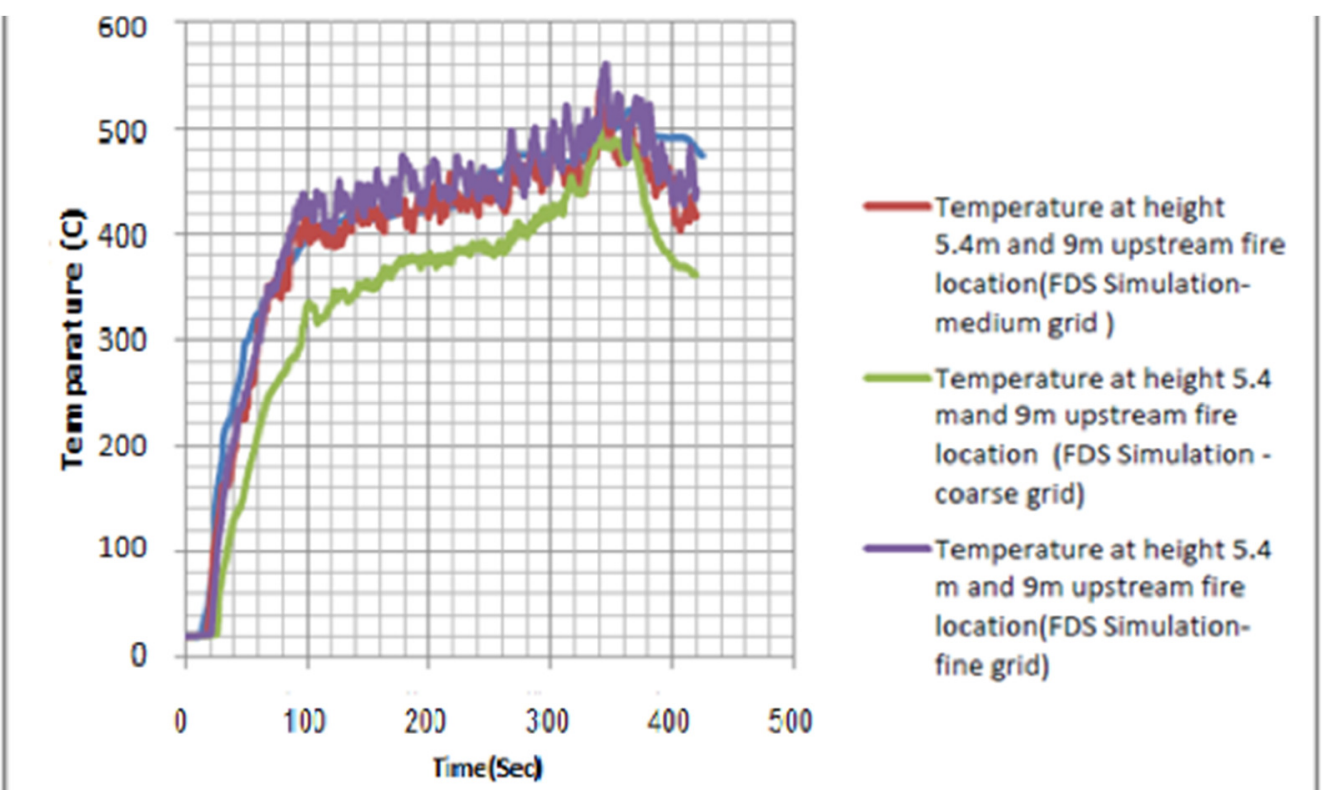

Fig. 7. Temperature variation with time at height $5.4 \mathrm{~m}$ and $9 \mathrm{~m}$ upstream fire location using different grid size. 


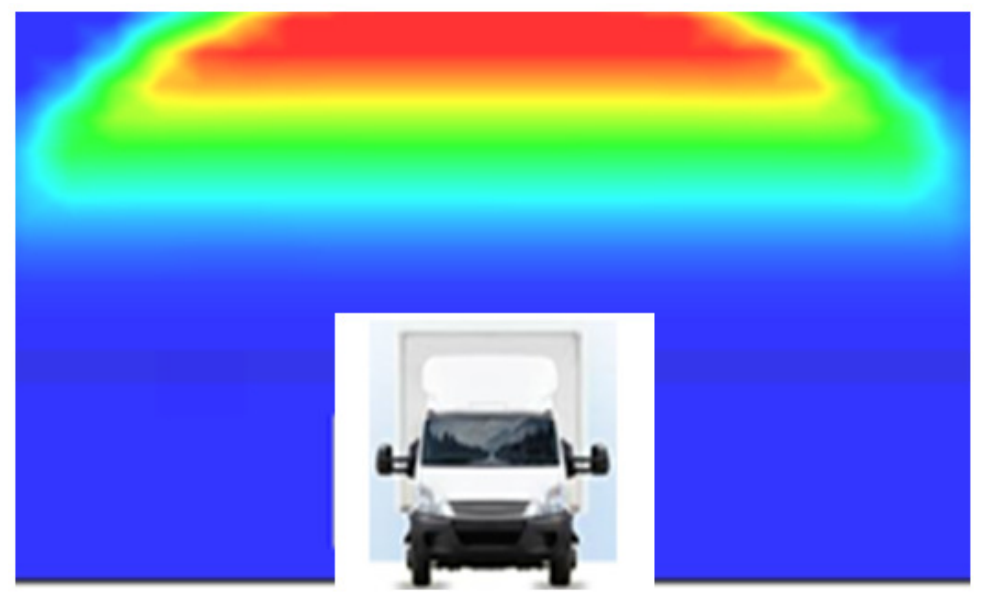

Fig. 8. Case \#1Temperature contour at $x=50 \mathrm{~m}$ downstream fire -At time $100 \mathrm{~s}$.

255
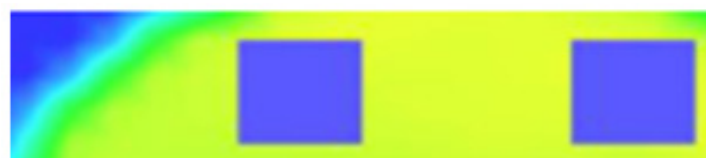

225

195

165

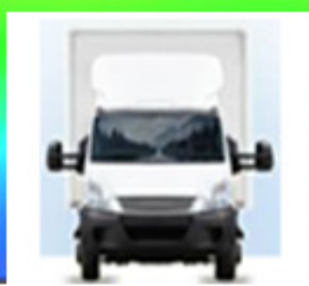

135

105

Fig. 9. Case \#1Temperature contour at $x=50 \mathrm{~m}$ downstream fire -At time $150 \mathrm{~s}$.

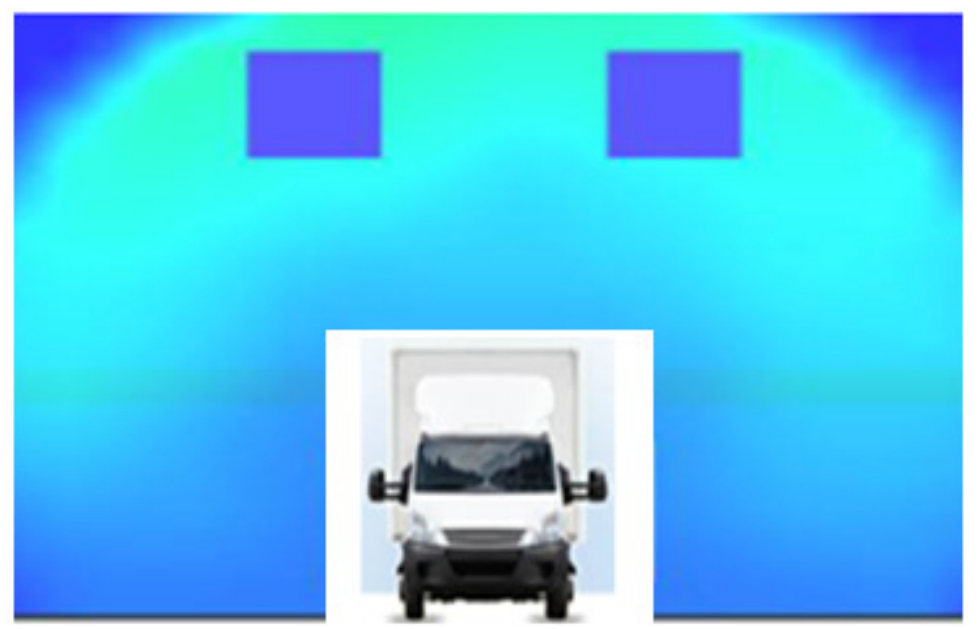

Fig. 10. Case \#1 Temperature contour at $x=50 \mathrm{~m}$ downstream fire -At time $300 \mathrm{~s}$. 


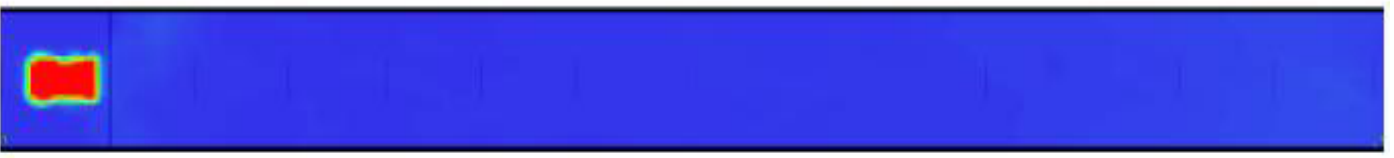

Fig. 11. Case \#1Temperature contour in zone \#2 at human level at time $100 \mathrm{~s}$

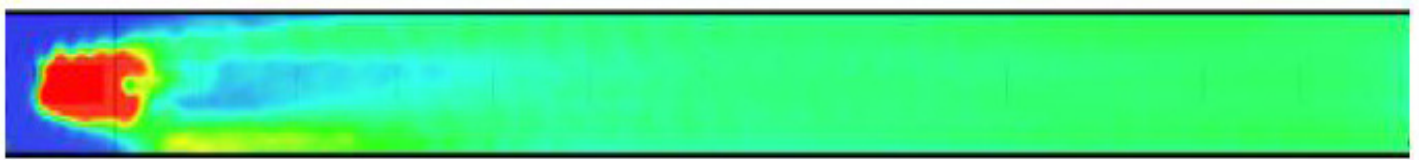

Fig. 12. Case \#1Temperature contour in zone \#2 at human level at time $150 \mathrm{~s}$.
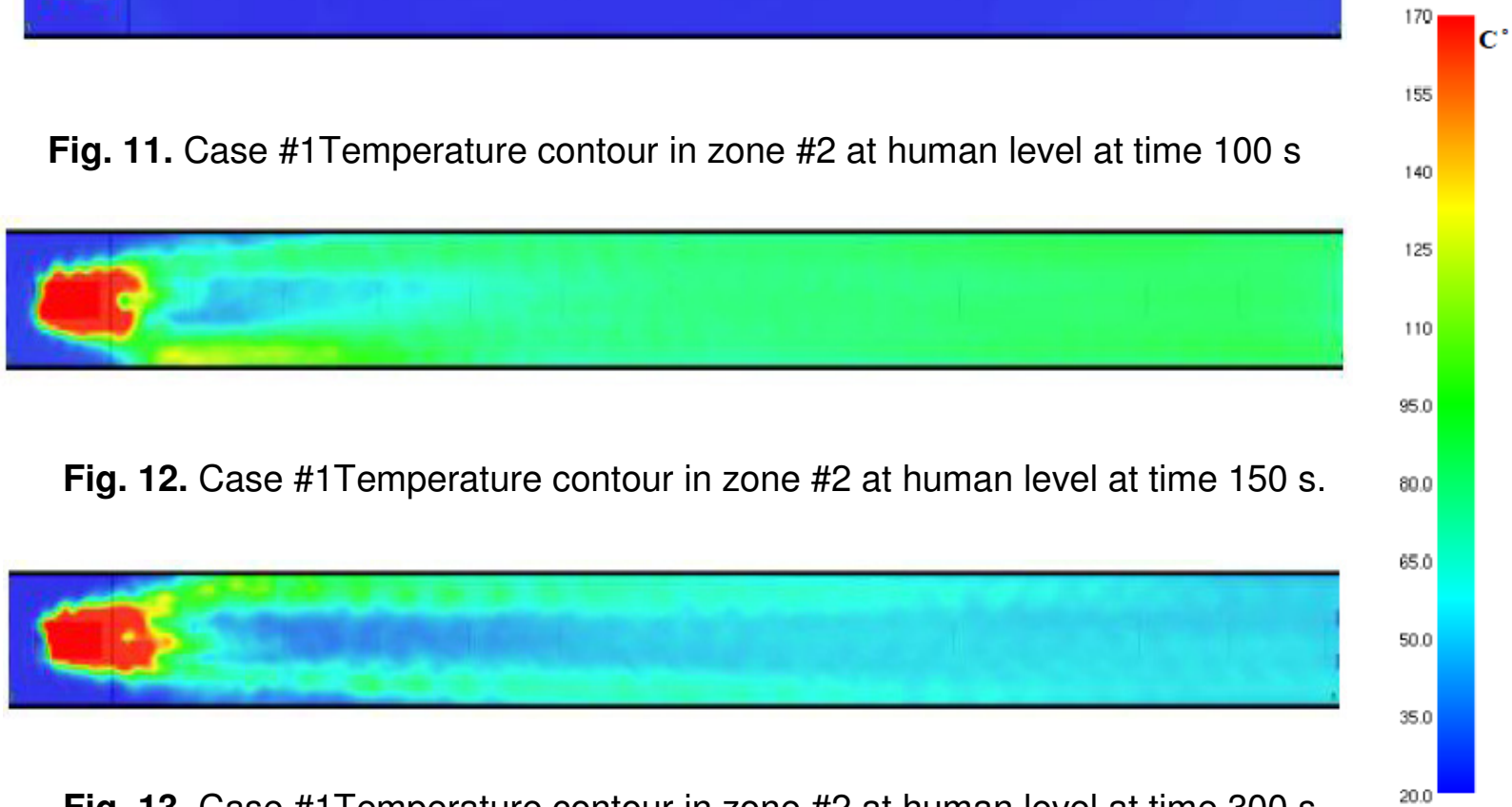

Fig. 13. Case \#1Temperature contour in zone \#2 at human level at time $300 \mathrm{~s}$.

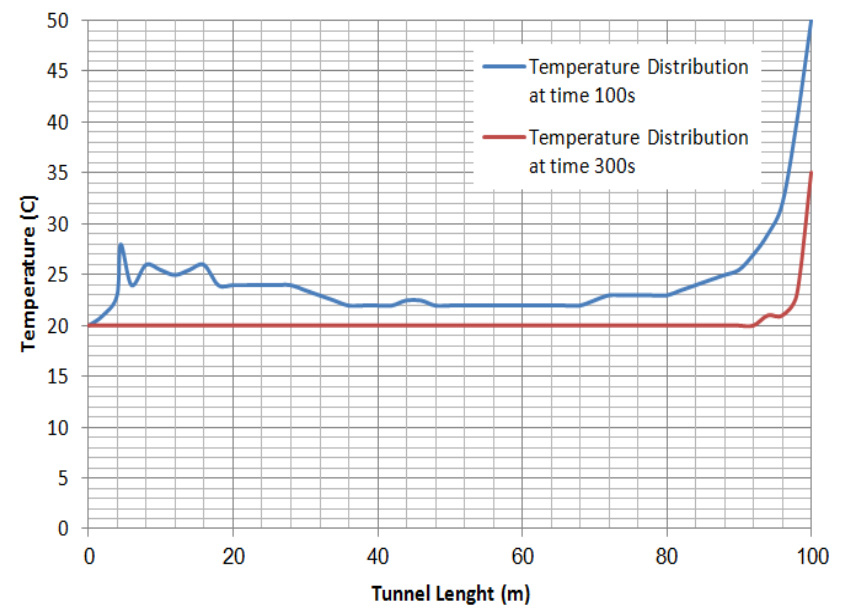

Fig. 14. Longitudinal temperature distribution at human level in upstream region.

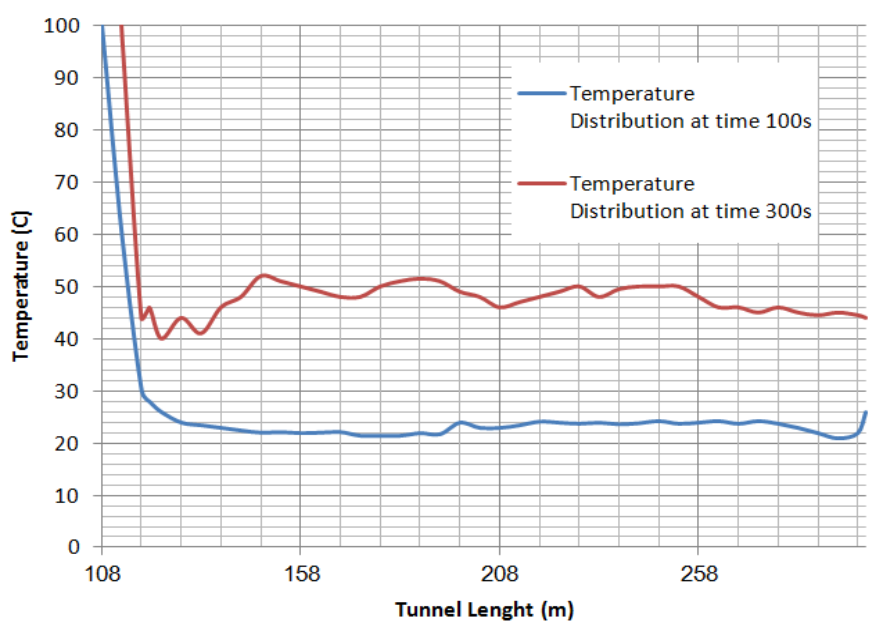

Fig. 15. Longitudinal temperature distribution at human level in downstream region. 


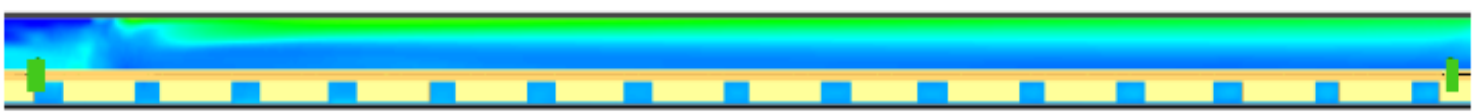

Fig. 16. Velocity Contours at mid plane in zone \#2 at time $100 \mathrm{~s}$.

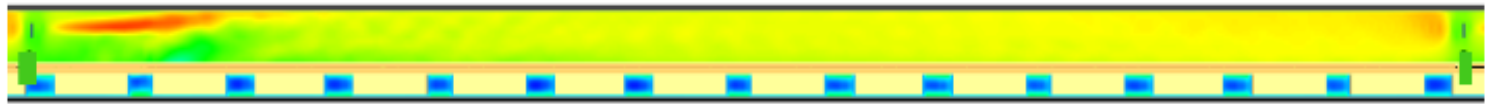

Fig. 17. Velocity Contours at mid plane in zone \#2 at time $150 \mathrm{~s}$.

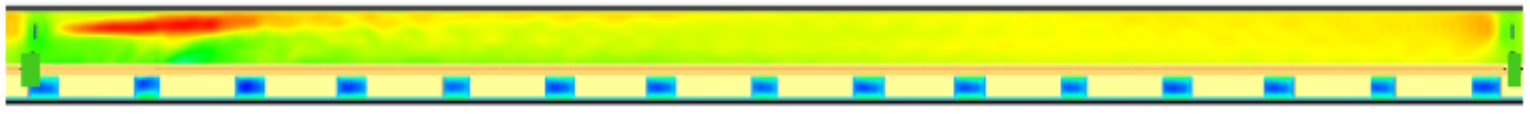

Fig. 18. Velocity Contours at mid plane in zone \#2 at time $300 \mathrm{~s}$.
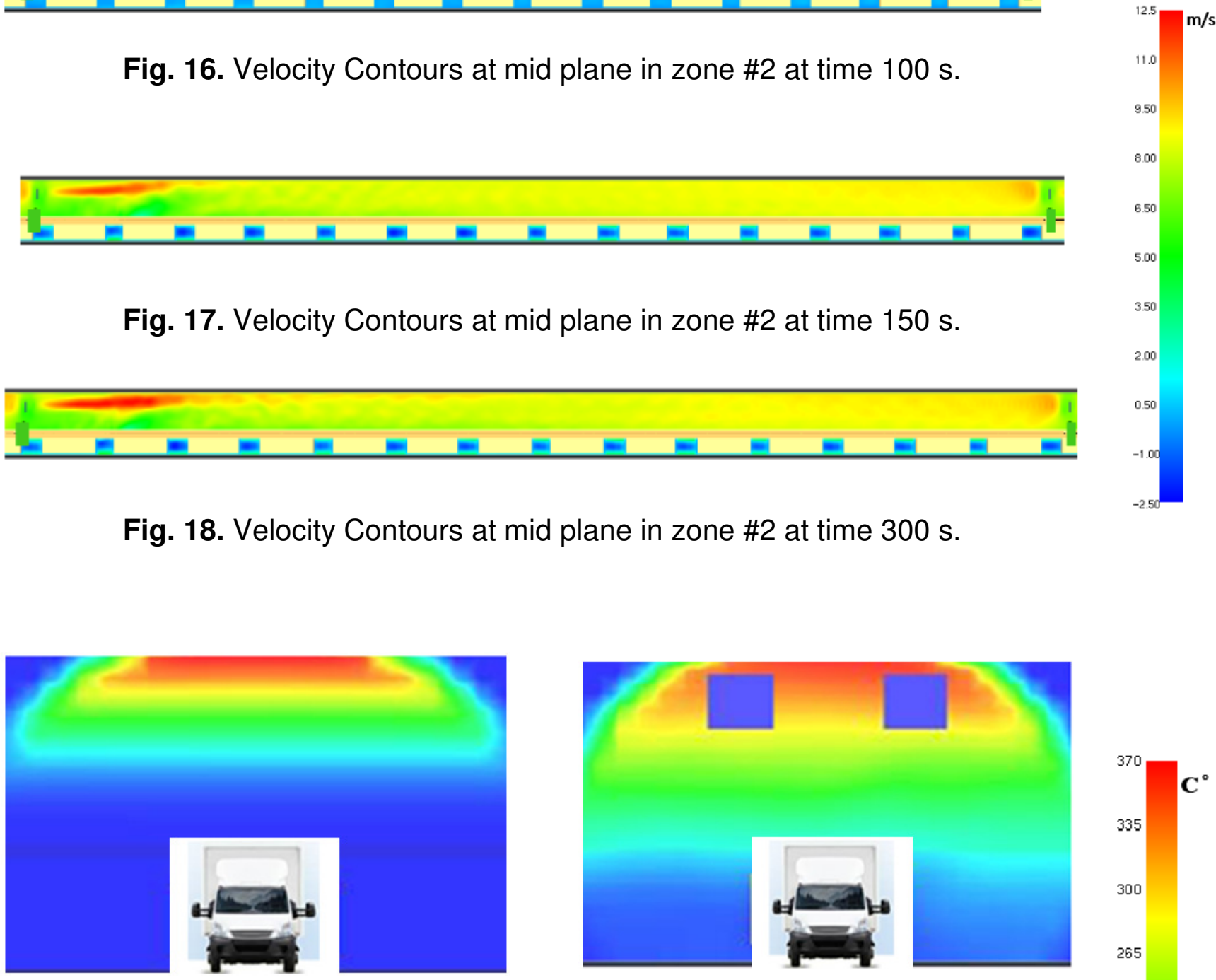

Fig. 19. Case \#2 Temperature contour at $50 \mathrm{~m}$ downstream fire at time 100 s before working of jet fans.

Fig. 20. Case \#2 Temperature contour at $50 \mathrm{~m}$ downstream fire at time 150s.

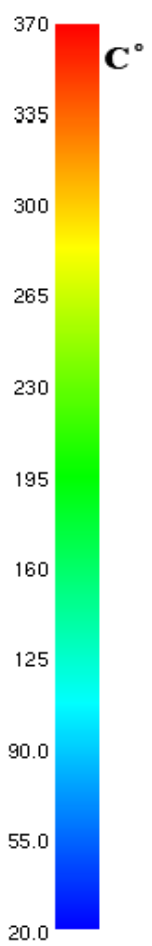

Fig. 21. Case \#2 Temperature contour at 50m downstream fire at time 300s. 
Fig. 22. Temperature contours in zone $\# 2$ at human level at time 100 s.

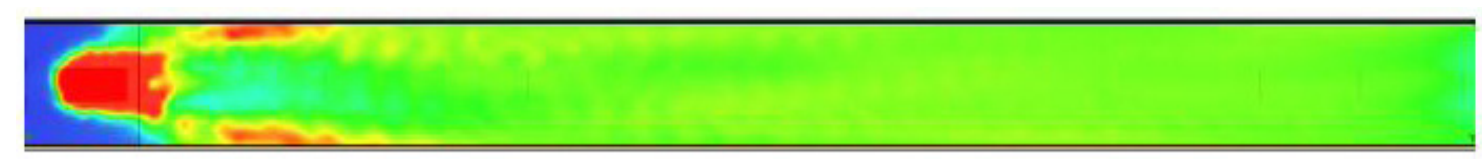

Fig. 24. Temperature contours in zone \#2 at human level at time 300s.

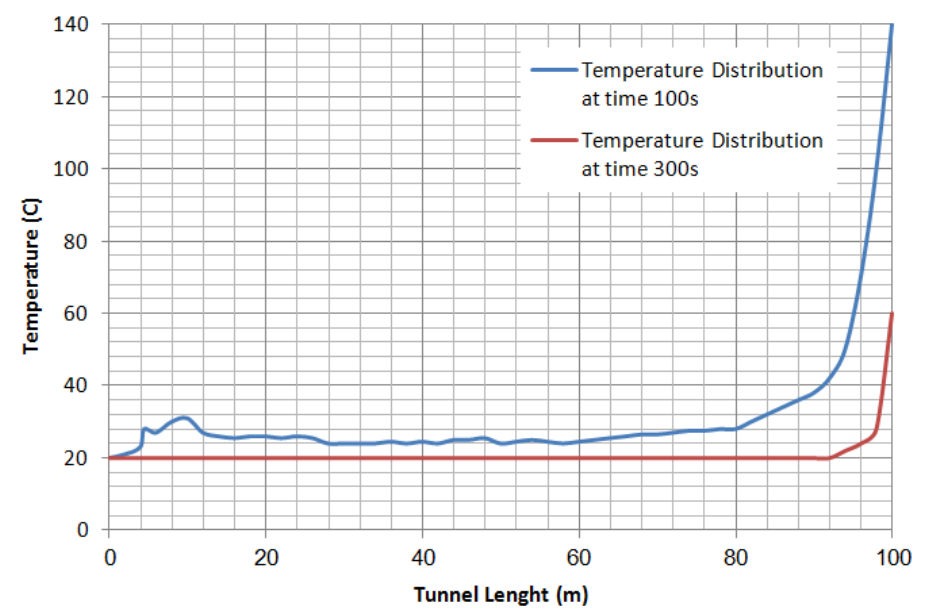

Fig. 25. Longitudinal temperature at human level in upstream region.

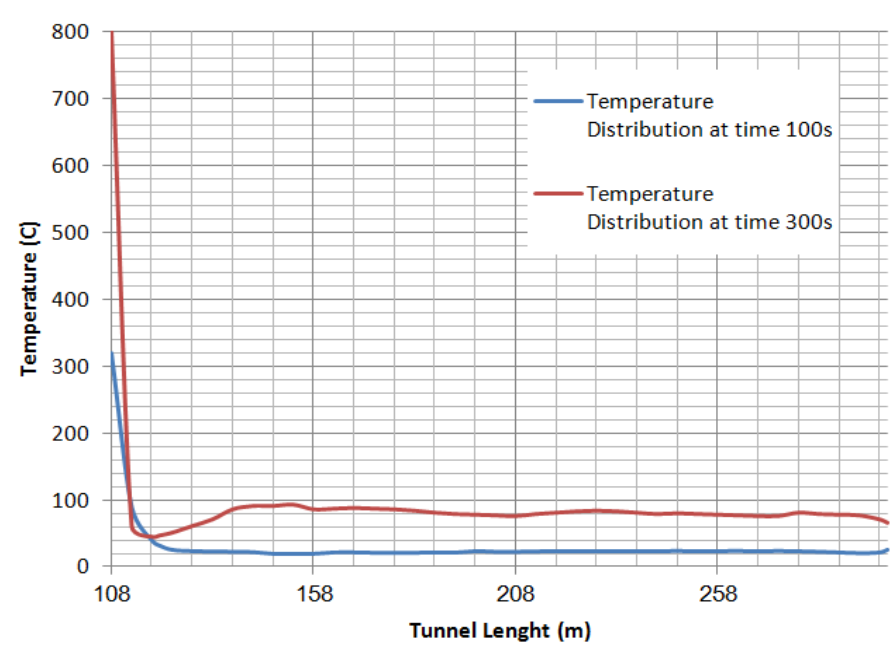

Fig. 26. Longitudinal temp. distribution distribution at human level in downstream. 
Fig. 27. Velocity contours at mid plane in Zone \#2 at time $100 \mathrm{~s}$.

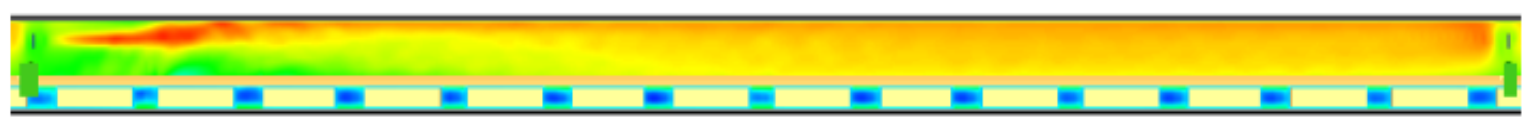

Fig. 28. Velocity contours at mid plane in Zone \#2 at time $150 \mathrm{~s}$.

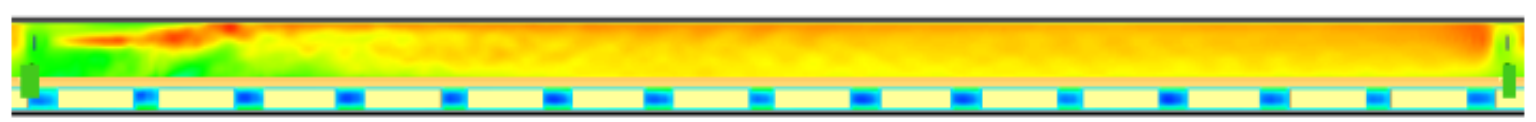

Fig. 29. Velocity contours at mid plane in Zone \#2 at time $300 \mathrm{~s}$.
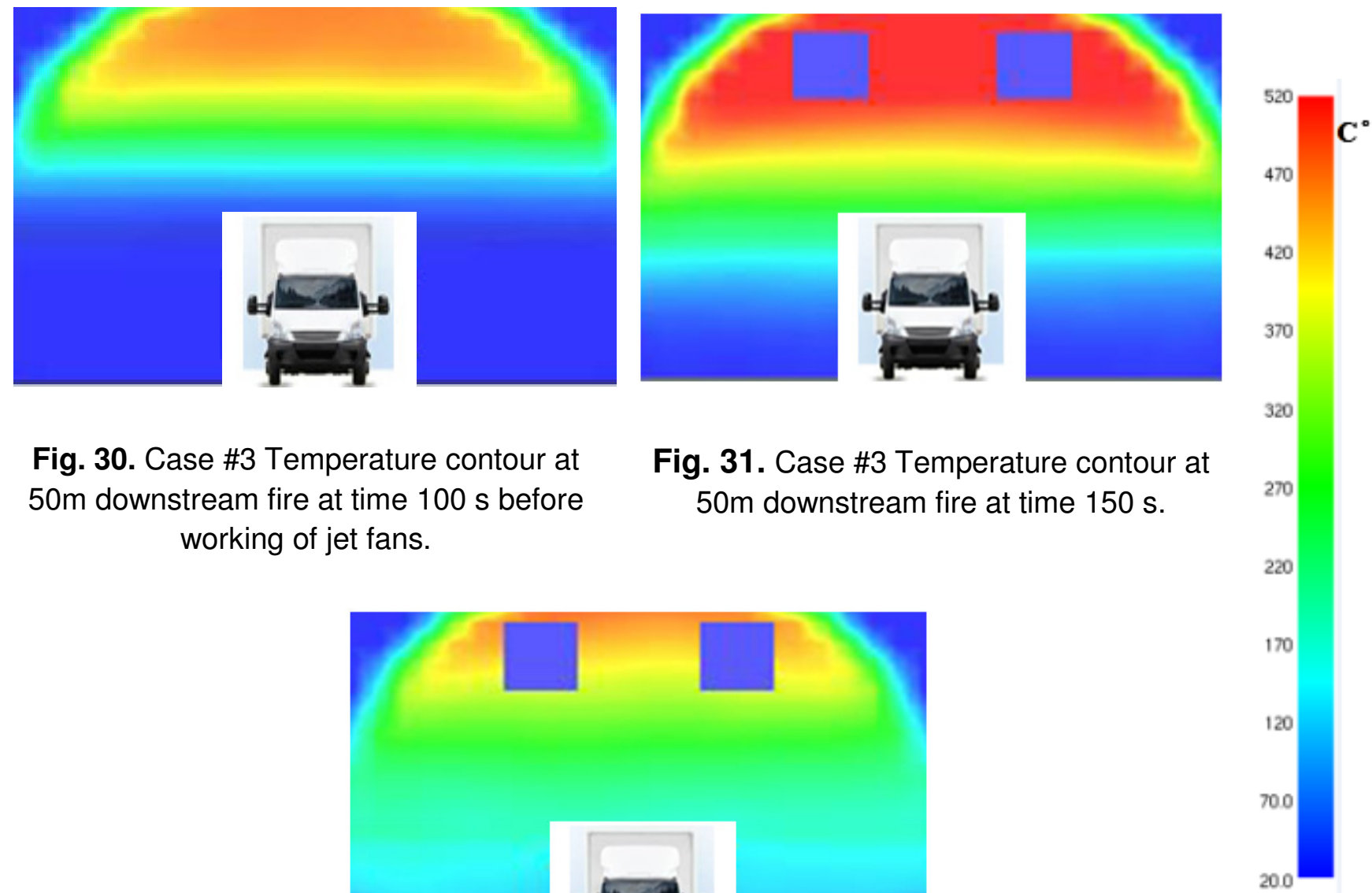

Fig. 30. Case \#3 Temperature contour at $50 \mathrm{~m}$ downstream fire at time $100 \mathrm{~s}$ before working of jet fans.

Fig. 31. Case \#3 Temperature contour at $50 \mathrm{~m}$ downstream fire at time $150 \mathrm{~s}$.

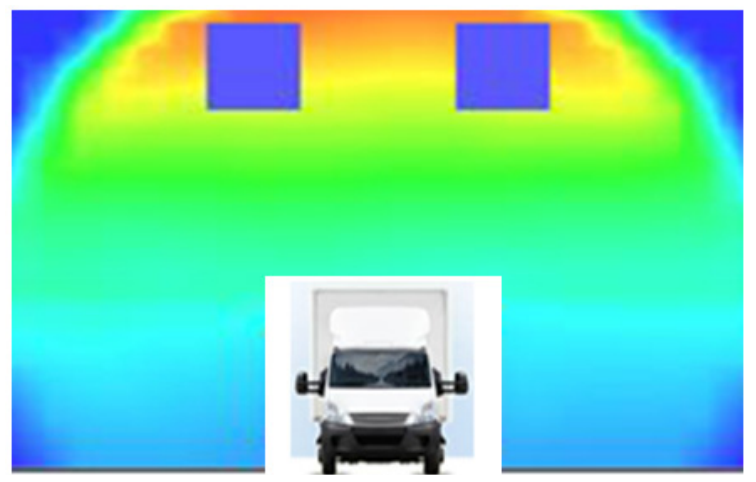

\section{/s}


Fig. 33. Temperature contours in zone \#2 at human level at time $100 \mathrm{~s}$.

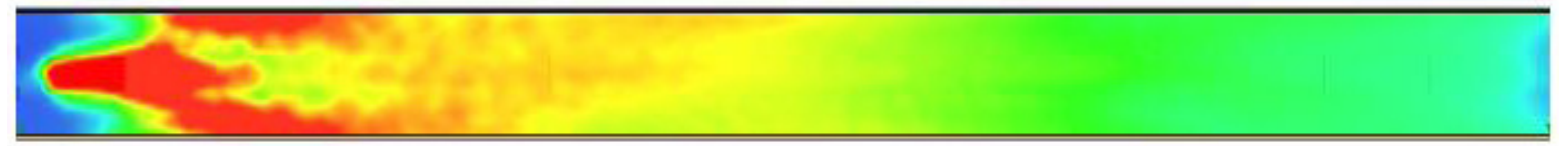

Fig. 34. Temperature contours in zone \#2 at human level at time $150 \mathrm{~s}$.

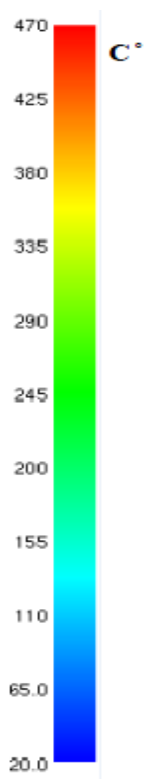

Fig. 35. Temperature contours in zone \#2 at human level at time $300 \mathrm{~s}$.

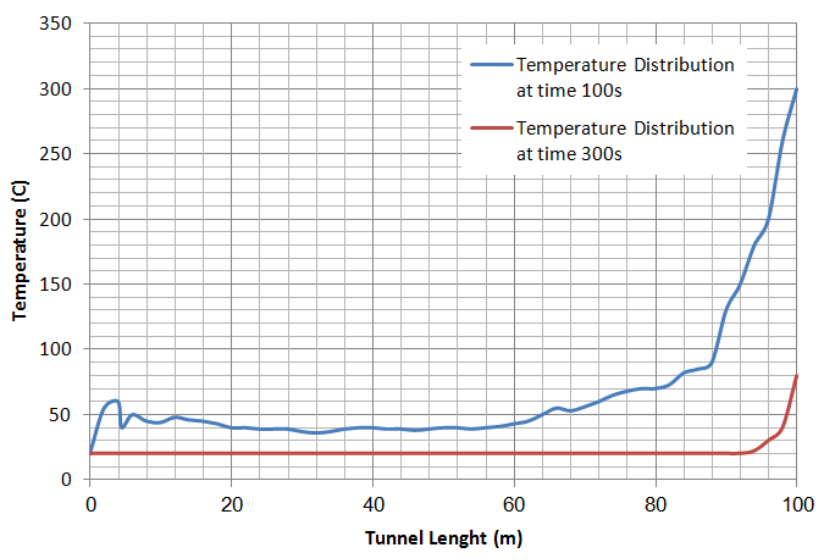

Fig. 36. Longitudinal temperature distribution at human level in upstream region.

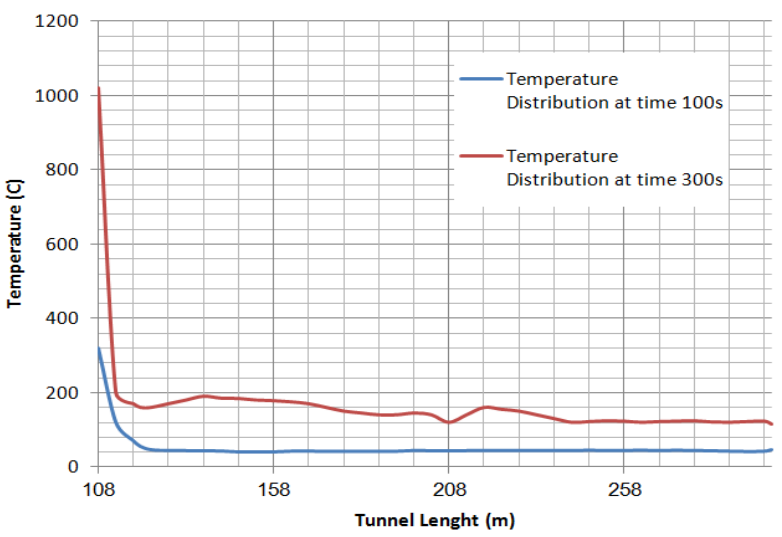

Fig. 37. Longitudinal temperature distribution at human level in downstream region. 
Fig. 38. Velocity contours at mid plane in Zone \#2 at time $100 \mathrm{~s}$.

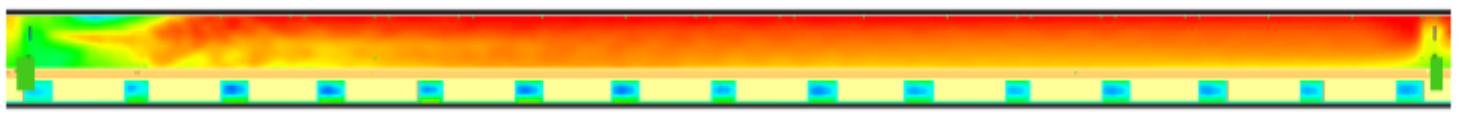

Fig. 39. Velocity contours at mid plane in Zone \#2 at time $150 \mathrm{s.}$

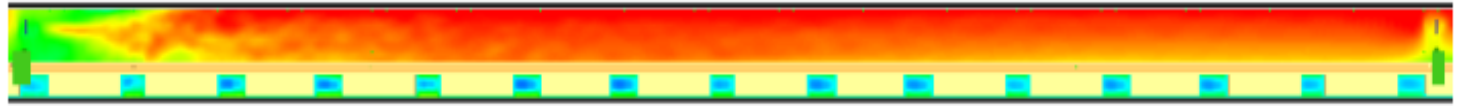

Fig. 40. Velocity contours at mid plane in Zone \#2 at time $300 \mathrm{~s}$.

\section{REFERENCES}

[1] Haukur Ingason, Fire Technology, SP Swedish National Testing and Research Institute.

[2] Beard, A., Fire safety in tunnels, Fire Safety J. 44 (2009) 276-278.

[3] Alarie, Y., Toxicity of fire smoke, Crit. Rev. Toxicol. 32 (2002) 259-289.

[4] Rafiei, M., Sturm, "Influence of fires on-air velocity measurements at downstream measurement locations", 7th International Conference Tunnel Safety and Ventilation, Graz, Austria,(2014) pp.265-272.

[5] C.G. Fan, J. Ji, Z.H. Gao, J.Y. Han and J.H. Sun. Experimental study of air entrainment mode with natural ventilation using shafts in road tunnel fires. International journal heat mass transfer.( 2013) 56, 750-757.

[6] Mehdi Rafiei, Numerical Simulation of a Full Scaled Fire Test of the Tunnel with Natural Ventilation, International Journal of Computer Applications (2015) 0975 - 8887.

[7] Leitner, A., The fire catastrophe in the Tauern Tunnel: experience and conclusions for the Austrian Guidelines, Tunnel Undergr. Sp. Technol. 16 (2001) 217-223.

[8] Kuang-Chung Tsaia, Hon-Hsiang Chena, Shin-Ku Lee Critical ventilation velocity for multi-source tunnel fires, Journal of Wind Engineering and Industrial Aerodynamics 10-11 (2010) 650-660.

[9] National Fire Protection Association. NFPA 502, "Standard for Road Tunnels,Bridges, and Other Limited Access Highways",2010.

[10] McGrattan, k., Hostikka, S., McDermott, R., Floyd, J., Weinschenk, C., Overholt, K. Fire Dynamics Simulator User's Guide (Version 6.1.1). (2014). NIST Special Publication 1019 Sixth Edition.

[11] Glenn P. Forney. Fire Dynamics Simulator Volume I: User's Guide (Version 6.1.11). (2014). NIST Special Publication 1017-1 Sixth Edition. 
[12] Blanchard, E., Boulet, P., Desanghere, S., Cesmat, E., Meyrand, R., Garo, J., and Vantelon, J., Experimental and numerical study of fire in a midscale test tunnel , Fire Safety Journal 47 (2012) 18-31.

[13] Oka, Y., and Atkinson, G., Control of Smoke Flow in Tunnel Fires, Fire Safety Journal 25 (1995) 305-322.

[14] Wu, Y., and Bakar, M., Control of smoke in tunnel using longitudinal ventilation systems (a study of the critical velocity), Fire Safety Journal 35 (2000) 363-390.

[15] Kunsch, J.P., Simple model for control of fire gases in a ventilated tunnel, Fire Saf. J. 37 (2002) 67-81. 